\title{
Is VAMLA/TEMLA the new standard of preresection staging of non-small cell lung cancer?
}

\author{
Sai Yendamuri, MBBS, and Todd L. Demmy, MD, FACS
}

\begin{abstract}
Accurate mediastinal staging is the hallmark of a good thoracic oncology program. Mediastinal lymph node staging is important for prognostication and to guide the administration of neoadjuvant and adjuvant therapy. In addition, accurate mediastinal staging is necessary for a fair comparison of different clinical studies. The most important surgical advance in mediastinal lymph node staging in the past few years is transcervical staging, by either sternal elevation or video-assisted mediastinoscopy. The present report summarizes the existing published data evaluating such an approach. (J Thorac Cardiovasc Surg 2012;144:S14-7)
\end{abstract}

Of the 3 elements constituting the TNM staging system, the most difficult element to accurately determine clinically is the nodal component. The reference standard for this component of staging is anatomic surgical resection accompanied by systematic lymph node dissection. Accurate preoperative nodal staging can help avoid futile surgery with its attendant mortality and morbidity. In addition, accurate preresection staging could help select patients for neoadjuvant therapy. Improvements in staging, particularly integrated positron emission tomography/computed tomography $(\mathrm{CT})$ have helped this process significantly. ${ }^{1} \mathrm{How}-$ ever, the limited specificity associated with imaging necessitates invasive staging for histologic confirmation. Thus, endoscopic ultrasound-guided fine needle aspiration ${ }^{2}$ represents a significant clinical advance. Although endoscopic staging offers a minimally invasive approach, the false-negative rate is high enough to warrant more invasive surgical staging when such testing is negative, especially in clinical situations in which the probability of nodal spread is high. Also, endoscopic staging does not perform well for restaging after neoadjuvant therapy. Thus, even with these advances, surgical preresection staging has a role in the management of lung cancer. The traditional method for surgical preresection staging of lung cancer has been mediastinoscopy. During the past few years, modifications of mediastinoscopy have been evaluated to enable systematic lymph node dissection, instead of sampling, to improve on the accuracy of transcervical surgical mediastinal staging. The 2 principal techniques that have evolved are transcervical extended mediastinal lymphadenectomy (TEMLA) and video-assisted mediastinal

From the Department of Thoracic Surgery, Roswell Park Cancer Institute, Buffalo, NY.

Disclosures: Authors have nothing to disclose with regard to commercial support.

Presented at the 3rd International Minimally Invasive Thoracic Surgery Summit, Boston, Massachusetts, October 7-8, 2011

Received for publication Sept 27, 2011; revisions received Feb 20, 2012; accepted for publication March 16, 2012; available ahead of print April 16, 2012.

Address for reprints: Todd L. Demmy, MD, FACS, Department of Thoracic Surgery, Roswell Park Cancer Institute, Buffalo, NY 14263 (E-mail: Todd.Demmy@ roswellpark.org).

$0022-5223 / \$ 36.00$

Copyright (c) 2012 by The American Association for Thoracic Surgery doi:10.1016/j.jtcvs.2012.03.038 lymphadenectomy (VAMLA). The most important studies evaluating these approaches are summarized in Table 1.

\section{TRANSCERVICAL EXTENDED MEDIASTINAL LYMPHADENECTOMY}

TEMLA extends traditional cervical mediastinoscopy using sternal elevation and video mediastinoscopy. All existing published reports of this technique have been from a single center in Zakopane, Poland. Detailed technical reports of this approach have been published both in manuscript form ${ }^{3}$ and as on-line videos (available from: http:// mmcts.ctsnetjournals.org/cgi/content/full/2006/1009/mmcts. 2005.001693 and http://www.ctsnet.org/sections/clinical resources/thoracic/expert_tech-44.html). The approach starts with a cervical collar incision akin to that for thyroidectomy. Superior and inferior subplatysmal flaps are raised. Bilateral recurrent laryngeal nerves are identified. A sternal lift is performed with a retractor to create space. A plane of dissection is established over the innominate artery, and the right paratracheal space is dissected out by direct visualization. Next, a pretracheal plane of dissection is established to dissect out the subcarinal space. The left paratracheal space is dissected after identification of the left recurrent laryngeal nerve, again by direct visualization. The aortopulmonary lymph node packet is then accessed after mobilization of the brachiocephalic vein. Using this procedure, levels $2 \mathrm{~L}, 4 \mathrm{~L}, 2 \mathrm{R}, 4 \mathrm{R}, 7,8,5$, and 6 can be dissected. An initial large report of this procedure in 256 patients demonstrated excellent staging results with an accuracy of $98 \%$ in a patient population with a disease prevalence of stage N2$\mathrm{N} 3$ of $31.3 \%$. The most frequent significant complication was recurrent laryngeal nerve injury, occurring in $2.3 \%$ of patients but permanent in only $0.8 \%{ }^{4}$ A head-to-head comparison of TEMLA with mediastinoscopy revealed significantly better sensitivity for TEMLA than for mediastinoscopy. ${ }^{5}$ In that small study, 41 patients were randomized to TEMLA vs mediastinoscopy, with TEMLA revealing metastatic disease in 7 patients and mediastinoscopy revealing metastatic disease in 3 patients. However, the results of mediastinoscopy in that study were much poorer than those reported by others. ${ }^{6}$ The accuracy of TEMLA in restaging disease after neoadjuvant therapy 


$$
\begin{aligned}
& \text { Abbreviations and Acronyms } \\
& \text { CT = computed tomography } \\
& \text { EBUS = endobronchial ultrasound } \\
& \text { TEMLA }=\text { transcervical extended mediastinal } \\
& \text { lymphadenectomy } \\
& \text { VAMLA = video-assisted mediastinal } \\
& \text { lymphadenectomy }
\end{aligned}
$$

again demonstrated stellar results, with a sensitivity of $95.5 \%$ and negative predictive value of $97.4 \%{ }^{7}$ In the study by Zielinski and colleagues, ${ }^{7}$ the overall rate of finding unexpected N3 disease was 3 of 63 patients. These results are better than any other method of restaging short of surgical resection. An indirect comparison of endobronchial ultrasound (EBUS)-fine needle aspiration with TEMLA for restaging was published by Szlubowski and colleagues. $^{8}$ In their study, patients underwent restaging with EBUS-fine needle aspiration. Those who were disease negative on EBUS then underwent TEMLA for restaging; $15 \%$ of patients with EBUS-negative findings had positive disease found using TEMLA. Despite only a sensitivity of $67 \%$, the investigators concluded that surgical restaging was not mandatory with negative EBUS findings in this setting. ${ }^{8}$

\section{VIDEO-ASSISTED MEDIASTINAL LYMPHADENECTOMY}

VAMLA uses a mediastinoscope that can be attached to a camera that displays the image on a video monitor. In addition, the blades of the mediastinoscope used can be spread along the axis of the handle, as well as at the tip, to create a wider space for dissection. The additional room enables bimanual dissection of lymph nodes similar to a video-assisted thoracic surgery approach. The method was pioneered by Hurtgen and colleagues. ${ }^{9}$ In an initial report of 46 patients, excellent diagnostic accuracy was reported, with 1 recurrent laryngeal nerve injury. A follow-up publication by the same group of 144 patients reported continued excellent staging accuracy. However, 5 recurrent laryngeal nerve injuries were reported. When the lung resection was performed in a staged fashion, marked scarring with difficult re-exploration was noted in $19.2 \%$ of these patients. Of these, 9 patients received neoadjuvant therapy. In this subset, the procedure was not possible in 2 patients because of the significant scarring and persistent bulky disease. An independent group also reported their experience with VAMLA in 108 patients with a strategy of concomitant thoracoscopic resection. ${ }^{10}$ No additional lymph nodes were identified by video-assisted thoracic surgery after VAMLA. In their series too, the main complication of VAMLA was recurrent laryngeal nerve injury in 5 patients.

\section{INITIAL ROSWELL EXPERIENCE}

We adopted TEMLA for patients with a high probability of having nodal disease, including those with large tumors, locally advanced tumors, or resection after neoadjuvant therapy. Unlike previous reports, TEMLA was performed at the same time as definitive resection, provided the frozen section analysis report was negative for N2 disease. Patients with extensive calcific atherosclerotic disease of the innominate artery or patients with previous neck surgery (including previous mediastinoscopy) were not chosen. The outcomes and nodal harvest were measured. In cases in which the nodes from a large dissected nodal packet were

\begin{tabular}{|c|c|c|c|c|c|}
\hline Investigator & Approach & Patients (n) & Compared with & Performance characteristics & Side effects \\
\hline Hurtgen et $\mathrm{al}^{9}$ & VAMLA & 46 & Thoracotomy & FNR $0 \%$ & 1 recurrent laryngeal nerve injury \\
\hline Leschber et al ${ }^{14}$ & VAMLA & 23 & Thoracotomy $(\mathrm{n}=18)$ & FNR $0 \%$ & Blood loss $>100 \mathrm{~mL}$ in $12 \%$ \\
\hline Witte et $\mathrm{al}^{15}$ & VAMLA & 144 & Thoracotomy $(\mathrm{n}=130)$ & $\begin{array}{l}\text { FNR } 0.9 \% \text {, sensitivity } 100 \%, \\
\text { specificity } 93.8 \%\end{array}$ & $\begin{array}{l}\text { Recurrent laryngeal nerve injury } \\
3.4 \% \text { patients }\end{array}$ \\
\hline Witte et $\mathrm{al}^{16}$ & VAMLA + VATS & 18 & VATS & $\begin{array}{l}\text { More stations and more lymph } \\
\text { nodes harvested by VAMLA+ } \\
\text { VATS }\end{array}$ & No difference \\
\hline Yoo et $\mathrm{al}^{10}$ & VAMLA & 108 & VATS resection $(\mathrm{n}=97)$ & FNR $0 \%$ & $\begin{array}{l}\text { Recurrent laryngeal nerve injury } \\
\text { in } 4.6 \% \text { patients }\end{array}$ \\
\hline Zielinski et $\mathrm{al}^{4}$ & TEMLA & 256 & Thoracotomy $(\mathrm{n}=138)$ & FNR $2.8 \%$ & $\begin{array}{l}\text { Recurrent laryngeal nerve palsy } \\
2.3 \%\end{array}$ \\
\hline Kuzdal et $\mathrm{al}^{5}$ & TEMLA & 21 & Mediastinoscopy $(\mathrm{n}=20)$ & $\begin{array}{r}\text { NPV of TEMLA } 100 \% \text { vs } \\
\text { mediastinoscopy } 66.7 \%\end{array}$ & $\begin{array}{l}\text { Operative time and pain intensity } \\
\text { greater in TEMLA }\end{array}$ \\
\hline Zielinski et $\mathrm{al}^{7}$ & TEMLA & 63 & Thoracotomy $(\mathrm{n}=42)$ & NPV of TEMLA $97.4 \%$ & \\
\hline
\end{tabular}
not counted, the volume of the sample was measured, and the nodal count was estimated at 1 node $/ 0.5 \mathrm{~cm}^{3}$. TEMLA was attempted on 19 patients and was successfully performed on 18, with 1 technical failure owing to severe adhesions. Of the 18 procedures, 1 was performed for metastatic

TABLE 1. Summary of studies of TEMLA/VAMLA

TEMLA, Transcervical extended mediastinal lymphadenectomy; VAMLA, video-assisted mediastinal lymphadenectomy; FNR, false-negative rate; VATS, video-assisted thoracic surgery; $N P V$, negative predictive value. 
thyroid cancer and the rest for lung cancer. Of those $17 \mathrm{pa}-$ tients, $12(70.6 \%)$ had received neoadjuvant chemotherapy. The median intensive care unit and hospital length of stay was 1 and 5 days, respectively. No TEMLA-related complications occurred, including recurrent laryngeal nerve injury. Of the 17 patients, $15(88.2 \%)$ also underwent concomitant surgical resection. The lymph node harvest data are listed in Table 2. A technical observation made during the conduct of these procedures was that the TEMLA procedure simplifies the dissection of the main pulmonary artery from the mainstem bronchus, the critical step in thoracoscopic pneumonectomy because a part of the dissection is completed during TEMLA. In addition, we now use electromyographic monitoring (requires avoidance of muscle relaxation), already routine for many thyroid operations, to help identify and demonstrate preservation of the recurrent nerves at TEMLA completion. This is especially useful to distinguish TEMLA-related nerve dysfunction from any transthoracic dissection related injury.

\section{SHOULD VAMLA/TEMLA BE THE NEW STANDARD?}

From published data, it is clear that preresection staging is accomplished most accurately using TEMLA or VAMLA compared to any other preresection investigation. However, this accuracy comes at a price - the most significant of which is recurrent laryngeal nerve injury. The current published data suggest a $1 \%$ rate of injury with TEMLA and a $3 \%$ to $5 \%$ rate of injury with VAMLA; however, this is in expert hands. It remains to be seen whether this accuracy can be replicated by other centers, because most data presented has been from only a few centers. If the safety and accuracy are replicable, surgeons should integrate this technology with their current practice philosophy. The yield of surgical mediastinal staging in the setting of a small peripheral lung cancer with no suggestion of mediastinal positivity by CT or positron emission tomography-CT scan is too low to justify the risk of TEMLA or VAMLA. ${ }^{11}$ Therefore, it is likely that this procedure will be adopted in situations that have a greater yield, just as we have done in our practice. These include larger tumors, central tumors, and tumors with a high uptake on positron emission tomography-CT. The inclusion of larger tumors in this decision rubric is supported by at least a few retrospective studies. ${ }^{12,13}$ However, 1 situation in which the argument for TEMLA/VAMLA to be the new standard of care is cogent is in restaging after neoadjuvant therapy. In this situation, if one believes that residual mediastinal disease precludes surgical resection, these methods will be superior to all other restaging methods and have a high potential for avoiding futile surgery.

A related, although different, question is the effect that such restaging might have on the overall outcome of patients with NSCLC. It might be a reasonable to consider disease detected by a larger operation such as TEMLA
TABLE 2. Tumor characteristics and outcomes of patient undergoing TEMLA at Roswell Park Cancer Institute

\begin{tabular}{|c|c|}
\hline Variable & Measure \\
\hline Total patients (n) & 19 \\
\hline Technical success rate (n) & $18 / 19(94.7)$ \\
\hline \multicolumn{2}{|l|}{ Pathologic finding (n) } \\
\hline Metastatic thyroid cancer & $1 / 19$ \\
\hline Lung cancer & $18 / 19$ \\
\hline \multicolumn{2}{|l|}{ Length of stay (d) } \\
\hline \multicolumn{2}{|l|}{ ICU } \\
\hline Median & 1 \\
\hline Range & $0-16$ \\
\hline \multicolumn{2}{|l|}{ Hospital } \\
\hline Median & 1 \\
\hline Range & $0-31$ \\
\hline Atrial fibrillation & $1 / 18(8.3)$ \\
\hline Patients with concomitant lung resection & $15 / 17(88.2)$ \\
\hline Pneumonia/ARDS & $2 / 18(16.7)$ \\
\hline Confusion & $1 / 18(8.3)$ \\
\hline \multicolumn{2}{|l|}{ Tumor characteristics } \\
\hline Neoadjuvant therapy & $12 / 17(70.6)$ \\
\hline Tumor involving chest wall & $1 / 17(5.9)$ \\
\hline Tumors $>6 \mathrm{~cm}$ & 2/17 (11.8) \\
\hline \multicolumn{2}{|l|}{ Lymph node harvest (n) } \\
\hline \multicolumn{2}{|l|}{$2 \mathrm{R}$} \\
\hline Median & 2 \\
\hline Range & $0-6$ \\
\hline \multicolumn{2}{|l|}{$4 \mathrm{R}$} \\
\hline Median & 4 \\
\hline Range & $0-14$ \\
\hline \multicolumn{2}{|l|}{$2 \mathrm{~L}$} \\
\hline Median & 0 \\
\hline Range & $0-3$ \\
\hline \multicolumn{2}{|l|}{$4 \mathrm{~L}$} \\
\hline Median & 2 \\
\hline Range & $0-19$ \\
\hline \multicolumn{2}{|l|}{7} \\
\hline Median & 4.5 \\
\hline Range & $1-16$ \\
\hline
\end{tabular}

Data in parentheses are percentages. TEMLA, Transcervical extended mediastinal lymphadenectomy; $I C U$, intensive care unit; $A R D S$, acute respiratory distress syndrome.

to be less relevant than that found by mediastinoscopy. This difficult question would take a large randomized clinical trial to answer and is unlikely to occur. In addition, no data are available that prove an improvement in locoregional recurrence rates with these extensive mediastinal staging procedures compared with endoscopic staging or mediastinoscopy.

\section{CONCLUSIONS}

TEMLA and VAMLA are improvements in conventional mediastinoscopy with excellent accuracy. The wider adoption of these procedures by the thoracic surgical community will help determine the reproducibility of the safety and accuracy data published thus far. If reproducible, TEMLA and 
VAMLA will constitute a new reference standard for preresection staging of non-small cell lung cancer.

\section{References}

1. Darling GE, Maziak DE, Inculet RI, Gulenchyn KY, Driedger AA, Ung YC, et al. Positron emission tomography-computed tomography compared with invasive mediastinal staging in non-small cell lung cancer: results of mediastinal staging in the Early Lung Positron Emission Tomography Trial. J Thorac Oncol. 2011;6: 1367-72.

2. Annema JT, van Meerbeeck JP, Rintoul RC, Dooms C, Deschepper E, Dekkers OM, et al. Mediastinoscopy vs endosonography for mediastinal nodal staging of lung cancer: a randomized trial. JAMA. 2010;304:2245-52.

3. Kuzdzal J, Zielinski M, Papla B, Szlubowski A, Hauer L, Nabialek T, et al. Transcervical extended mediastinal lymphadenectomy-the new operative technique and early results in lung cancer staging. Eur J Cardiothorac Surg. 2005;27: 384-90.

4. Zielinski M. Transcervical extended mediastinal lymphadenectomy: results of staging in two hundred fifty-six patients with non-small cell lung cancer. $J$ Thorac Oncol. 2007;2:370-2.

5. Kuzdzal J, Zielinski M, Papla B, Urbanik A, Wojciechowski W, Narski M, et al. The transcervical extended mediastinal lymphadenectomy versus cervical mediastinoscopy in non-small cell lung cancer staging. Eur J Cardiothorac Surg. 2007;31:88-94

6. Patterson GA, Ginsberg RJ, Poon PY, Cooper JD, Goldberg M, Jones D, et al. A prospective evaluation of magnetic resonance imaging, computed tomography, and mediastinoscopy in the preoperative assessment of mediastinal node status in bronchogenic carcinoma. J Thorac Cardiovasc Surg. 1987;94:679-84.

7. Zielinski M, Hauer L, Hauer J, Nabialek T, Szlubowski A, Pankowski J. Nonsmall-cell lung cancer restaging with transcervical extended mediastinal lymphadenectomy. Eur J Cardiothorac Surg. 2010;37:776-80.
8. Szlubowski A, Herth FJ, Soja J, Kolodziej M, Figura J, Cmiel A, et al. Endobronchial ultrasound-guided needle aspiration in non-small-cell lung cancer restaging verified by the transcervical bilateral extended mediastinal lymphadenectomya prospective study. Eur J Cardiothorac Surg. 2010;37:1180-4.

9. Hurtgen M, Friedel G, Toomes H, Fritz P. Radical video-assisted mediastinoscopic lymphadenectomy (VAMLA) - technique and first results. Eur J Cardiothorac Surg. 2002;21:348-51.

10. Yoo DG, Kim YH, Kim DK, Kim HR, Park SI. Clinical feasibility and surgical benefits of video-assisted mediastinoscopic lymphadenectomy in the treatmen of resectable lung cancer. Eur J Cardiothorac Surg. 2011;40:1483-6.

11. Meyers BF, Haddad F, Siegel BA, Zoole JB, Battafarano RJ, Veeramachaneni N et al. Cost-effectiveness of routine mediastinoscopy in computed tomographyand positron emission tomography-screened patients with stage I lung cancer. J Thorac Cardiovasc Surg. 2006;131:822-9.

12. Hsu CP, Hsia JY, Chang GC, Chuang CY, Shai SE, Yang SS, et al. Surgical-pathologic factors affect long-term outcomes in stage IB (pT2 N0 M0) non-small cell lung cancer: a heterogeneous disease. J Thorac Cardiovasc Surg. 2009;138: 426-33.

13. Lardinois D, Suter H, Hakki H, Rousson V, Betticher D, Ris HB. Morbidity, survival, and site of recurrence after mediastinal lymph-node dissection versus systematic sampling after complete resection for non-small cell lung cancer. Ann Thorac Surg. 2005;80:268-75.

14. Leschber G, Holinka G, Linder A. Video-assisted mediastinoscopic lymphadenectomy (VAMLA) — a method for systematic mediastinal lymph node dissection. Eur J Cardiothorac Surg. 2003;24:192-5.

15. Witte B, Wolf M, Huertgen M, Toomes H. Video-assisted mediastinoscopic surgery: clinical feasibility and accuracy of mediastinal lymph node staging. Ann Thorac Surg. 2006;82:1821-7.

16. Witte B, Messerschmidt A, Hillebrand H, Gross S, Wolf M, Kriegel E, et al. Combined videothoracoscopic and videomediastinoscopic approach improves radicality of minimally invasive mediastinal lymphadenectomy for early stage lung carcinoma. Eur J Cardiothorac Surg. 2009;35:343-7. 